\title{
BMJ Open Expectations and illness perceptions as predictors of benefit recipiency among workers with common mental disorders: secondary analysis from a randomised controlled trial
}

\author{
Camilla Løvvik, ${ }^{1,2}$ William Shaw, ${ }^{3,4}$ Simon Øverland, ${ }^{2,5}$ Silje Endresen Reme ${ }^{1}$
}

To cite: Løvvik C, Shaw W, Øverland $\mathrm{S}$, et al. Expectations and illness perceptions as predictors of benefit recipiency among workers with common mental disorders: secondary analysis from a randomised controlled trial. BMJ Open 2014;4: e004321. doi:10.1136/ bmjopen-2013-004321

- Prepublication history for this paper is available online. To view these files please visit the journal online (http://dx.doi.org/10.1136/ bmjopen-2013-004321)

Received 23 October 2013 Revised 20 January 2014 Accepted 10 February 2014

CrossMark

For numbered affiliations see end of article.

Correspondence to Dr Camilla Løvvik; camilla.lovvik@uni.no

\section{ABSTRACT}

Objective: Common mental disorders (CMDs) are among the leading causes of sick leave, and more knowledge on factors related to work participation and return-to-work (RTW) in CMDs is needed. The aim of this study was to investigate RTW-expectations and illness perceptions as predictors of benefit recipiency in CMDs.

Design: Study participants were enrolled in a randomised controlled trial and reported CMDs as a main obstacle for work participation. Three prespecified subgroups were included: people at risk of going on sick leave, people on sick leave ( $>3$ weeks) or people on long-term benefits. Baseline questionnaire data and registry data at baseline and 6 months were used to investigate predictors of benefit recipiency at 6 -month follow-up. Benefit recipiency included sickness benefits, disability pension, work assessment allowance and unemployment benefits.

Results: In this study, uncertain and negative RTWexpectations were strong predictors of benefit recipiency at 6 months follow-up. Illness perceptions predicted benefit recipiency in the unadjusted model, but not in the fully adjusted model. In the subgroup on sick leave, uncertain and negative RTW-expectations predicted benefit recipiency, while in the subgroup of people at risk of going on sick leave, negative RTWexpectations predicted benefit recipiency. In the subgroup on long-term benefits, only female gender predicted benefit recipiency.

Conclusions: For people with CMDs, uncertain and negative RTW-expectations predict later benefit recipiency, and expectations seem particularly important for those at risk of or on sick leave. For those at risk of sick leave, benefit recipiency at followup denoted a transition onto sick leave or long-term benefit, while those on sick leave had remained so or were receiving long-term benefits. Addressing RTWexpectations in occupational healthcare services or vocational rehabilitation might be beneficial in early stages or even prior to a sick leave episode.

Trial registration: http://www.clinicaltrials.gov, NCT01146730.

\section{Strengths and limitations of this study}

- Our study population consisted of persons at risk of sick leave, currently on sick leave or on longterm benefits due to common mental disorders (CMDs). This allowed investigation of RTW-expectations and illness perceptions as predictors of future benefit recipiency across subgroups on different stages in the transition between work and sick leave or long-term benefits.

- Benefit recipiency at 6-month follow-up was measured using complete and objective data from national registries on sick leave and benefits.

- A version of the Brief Illness Perceptions Questionnaire (B-IPQ) using the generic term 'your illness' rather than 'common mental disorders' was used. Hence, participants may have given responses based on illnesses other than CMDs.

- In this study, RTW-expectations were measured by one single item. Applying more refined and extensive measures could have provided different results regarding the predictive value of RTWexpectations.

\section{INTRODUCTION}

Work contributes to financial stability and offers a structure to everyday life, possibilities for personal development and social interaction; all factors that are found to promote good mental health and well-being. ${ }^{1}$ Common mental disorders (CMDs) - most often symptoms of anxiety and depression-pose a specific threat to work participation by restricting individuals' employability, reducing functionality, and thereby also negatively affecting income, self-esteem and quality of life. ${ }^{2}{ }^{3}$ In the UK, CMDs have been found to account for a large proportion of all long-term sick leave. ${ }^{4}$ In Norway, CMDs account for approximately $20 \%$ of sick leave episodes and about one-third of all disability pensions. ${ }^{5}$ Increased risk for prolonged sick leave ${ }^{6}$ and work disability ${ }^{7}$ has 
been found for CMDs, and of those sick listed with CMDs for more than 6 months, only $50 \%$ manage to return-to-work (RTW) ${ }^{8}$ A recent study from the USA found a lifetime prevalence of $33.7 \%$ for any anxiety disorder and $21.4 \%$ for any mood disorder. ${ }^{9}$ Hence, CMDs potentially affect a large proportion of the working age population. As disability pensions for CMDs, on average, are awarded at a younger age, the affiliated loss of working years is immense. ${ }^{10}$ Thus, CMDs are not only costly for the individual but for the greater society as well. Owing to their high prevalence and disabling and potentially catastrophic occupational outcomes, CMDs represent a major challenge to occupational health. To improve RTW in CMDs, as well as to help workers struggling with CMDs to maintain their work participation, more knowledge about factors acting as barriers for work participation or RTW in CMDs is needed. ${ }^{11}$

The volume of studies on what hinders or facilitates work participation in CMDs is growing, and findings show that predictors of RTW in CMDs are high and of a wide range. ${ }^{8} 1213$ Factors such as gender, self-rated health status, illness duration and symptom severity ${ }^{14}$ all predict RTW in CMDs. Factors related to work, health risk behaviours, social status as well as medical factors have also been found to act as barriers for RTW after episodes of poor mental health. ${ }^{8}$ In recent years, several studies have pointed out that RTW following sick leave is a multifaceted and complex process. ${ }^{15} 16$

The transition from work to sick leave and from sick leave to disability or back to work has been described as a process that requires decisions. ${ }^{11}$ It is possible that the decision to RTW is influenced by the individuals' beliefs in his or her ability to attain work-related goals. Recent studies have, therefore, looked at behaviour-specific selfefficacy beliefs such as RTW self-efficacy, ${ }^{17}$ and found this to strongly predict RTW in CMDs. ${ }^{18}$ Self-efficacy, defined as "the belief in ones' abilities to organize and execute the courses of action required to produce given attainments" 19 is central to initiation and perseverance of behaviour. ${ }^{20}$ RTW-expectations are closely related to RTW self-efficacy, and in a study on sick-listed temporary agency workers, it was found that expecting a full RTW, as well as perceiving ones' own health as moderate to good, strongly predicted actual RTW. ${ }^{21}$ RTW-expectations and RTW self-efficacy are presumably amendable factors, and it might prove useful to target these in occupational healthcare or as part of vocational rehabilitation interventions. However, in order to successfully do so, more information on RTW-expectations as predictors of work status and what comprises these expectations is needed.

In other health conditions such as myocardial infarction and musculoskeletal disorders, complex psychological constructs such as people's beliefs about their illness or diagnosis (illness perceptions) have been found to predict RTW. $^{22}$ Illness perceptions consist of cognitive and emotional representations that guide health behaviours and have been suggested to impact on the transition from disease to health and work-related outcomes. ${ }^{23}$
Although the relation between illness perceptions and work participation has been investigated in other health conditions, little is known about the impact these selfregulatory processes have on actual work status in CMDs. ${ }^{22} 24$ To the best of our knowledge, the impact of illness perceptions on work status in CMDs has not been studied longitudinally.

A recent cross-sectional study of the association between illness perceptions and RTW-expectations in CMDs found a strong and salient relationship between the two. ${ }^{25}$ Maladaptive illness perceptions were associated with uncertain and negative RTW-expectations, with stronger associations for the negative RTW-expectations. The findings further indicate that to understand how illness perceptions and RTW-expectations relate to each other and to work-related outcomes in CMDs, longitudinal designs are necessary. ${ }^{25}$

People struggling with work participation due to CMDs may be facing barriers dependent on situational factors, such as the availability of employment. It is likely that workers at risk of sick leave find themselves in a situation where work participation is more available to them than to a person who is on sick leave or on long-term benefits. The process of transitioning between work participation and benefit recipiency, such as sick leave or long-term benefits, is likely to involve decisions influenced by a persons' current situation. Thus, a person at risk of sick leave will have to decide to maintain work status, while a person on sick leave will have to decide to initiate the RTW-process. A person on long-term benefits may face other important barriers, such as seeking new employment in addition to being motivated for the RTW-process. Because of these different situational barriers, it is possible that RTWexpectations and illness perception act differently as predictors of benefit recipiency.

Although some interventions aiming to increase RTW in CMDs exist ${ }^{26}$ there is still a need for more knowledge concerning specific factors to target and modify in order to continue the development and improvement of successful RTW-interventions in CMDs.

In keeping with the notion of the transition between work, sick leave and disability as a process demanding different decisions at different stages, knowing more about how RTW-expectations and illness perceptions act as predictors of benefit recipiency across different stages in this process is important.

\section{OBJECTIVES}

The aim of this study was to examine whether RTW-expectations and illness perceptions predicted benefit recipiency in a population struggling with work participation due to CMDs, and whether the predictors differed in three prespecified subgroups (at risk of sick leave, on sick leave or on long-term benefits). Based on our previous cross-sectional study, ${ }^{25}$ we hypothesised negative RTW-expectations and perceiving severe 
consequences from illness could predict receiving benefits 6 months later.

This was examined through the specific aims: to (1) examine whether RTW-expectations and illness perceptions predicted benefit recipiency 6 months later overall, and further (2) to investigate the relative predictive contribution of RTW-expectations and illness perceptions after adjustment for confounders. As a second step, these analyses were repeated for each separate subgroup defined by baseline work status as the interpretation of results could differ accordingly.

\section{METHODS}

Design

The At Work and Coping Trial (AWaC) (Trial registration -http://www.clinicaltrials.gov, NCT01146730) is a randomised controlled multicentre trial evaluating the effect of work-focused cognitive behavioural therapy and an adaptation of individual placement and support on RTW in CMDs. The trial started in June 2010 and includes 1193 participants. Participants were referred to the trial not only from their general practitioners (GPs) or local national insurance offices, but also by self-referral after receiving information through websites or advertisement posters in GPs offices. A detailed overview of participant flow and enrolment has previously been published. ${ }^{25}$ In the AWaC trial, an important criterion for inclusion was the participants' own experience of CMDs as an obstacle for work participation regardless of actual sick leave status. This was clearly stated in brochures, posters and on websites. Hence, the $\mathrm{AWaC}$ trial included participants self-reporting to be at risk of going on sick leave, currently on sick leave or on long-term benefits due to CMDs. Additional inclusion criteria were: age 18-60 years, no known severe psychiatric illness, no risk of suicide or ongoing substance abuse and no current engagement in individual psychotherapy elsewhere. An explicit willingness to either maintain work participation or RTW was also required.

Prior to inclusion, all participants underwent a $30 \mathrm{~min}$ interview where they were screened for eligibility and given more detailed information about the study. Eligible and willing participants provided informed consent and filled in the baseline questionnaire. This questionnaire included various measures on demographic variables and measures on mental and somatic health problems. The trial had two arms where the control condition consisted of usual care, mainly follow-up from GPs, other RTW-interventions or occupational healthcare. No effect of the intervention was found on RTW at 6-month follow-up. For the purpose of this study, the groups were not analysed separately, but group allocation (intervention vs control) was included as a covariate in the logistic regression models.

In the current study, we applied a longitudinal design with 6-month follow-up. Study procedures were reviewed and approved by The Regional Ethics Committee, and all Helsinki declaration principles were followed.

\section{Confounders}

Instruments measuring health status included the Hospital Anxiety and Depression Scale (HADS) ${ }^{27}$ for CMDs and the subjective health complaints (SHC) inventory $^{28}$ for subjective health problems. Self-reported health status was measured by one question in the wording "How would you describe your own health?" with answers ranging from 'Very good' to 'Very poor' on a five-point scale. Illness duration was measured by a single item asking participants how long they had had mental health problems (in years). Beliefs concerning the impact of work participation on CMDs were assessed by asking participants "If you continue working, how do you think it will affect your complaints?" Answers were given on a five-point scale ranging from "It will worsen my condition" to "It will be very beneficial". Participants were also asked whether they had signed private disability insurance agreements (yes/no). A Norwegian standard for classification of occupations was used to group self-reported occupational titles into either blue-collar or white-collar work. This standard complies with the ISCO-88 (COM) standards.

\section{Predictors}

\section{RTW-expectations}

RTW-expectations were assessed by asking participants to respond to the following statement: "I expect to be back at work within the next few weeks". Thus, for the subgroup at risk of sick leave, the response to this item would imply 'maintaining work status'. For the other two subgroups (on sick leave and on long-term benefits), the response to this item would imply an expectation to RTW. For the purposes of this article, however, the responses from all participants were labelled 'RTW-expectations'. The participants responded on a five-point Likert scale ('strongly agree' to 'strongly disagree'). Responses were grouped into three types comprising those who strongly agreed or agreed into positive RTW-expectations, those answering 'neither agree nor disagree' into uncertain RTW-expectations and those either disagreeing or strongly disagreeing into negative RTW-expectations.

\section{IIIness perceptions}

Illness perceptions were measured using the Brief Illness Perception Questionnaire (B-IPQ) ${ }^{29}$ This nine-item questionnaire provides a rapid and reliable measurement of illness perceptions. Items one through eight are rated on a 0-10 response scale. The ninth B-IPQ item is open-ended and registers attribution of causal mechanisms. All nine items were analysed separately in the current study.

\section{Outcome}

The outcome measure (benefit recipiency) was based on registry information from complete and objective national registries on sick leave and benefits. The outcome variable was dichotomised so that those who at follow-up received any health-related benefits (disability pension, work assessment allowance, unemployment benefit or sickness benefits) from the national welfare 
service were coded ' 1 ', whereas those who did not receive any such benefits at follow-up were coded ' 0 '.

\section{Statistical analysis}

First, RTW-expectations and illness perceptions were examined as individual predictors of benefit recipiency at 6-month follow-up in the study population as a whole. Thus, these first analyses included participants at risk of sick leave, currently on sick leave or on long-term benefits. The illness perception and RTW-expectation variables were examined as predictors one at a time, using binary logistic regression analysis. The outcome predicted in all analyses was participants being registered as on sick leave or on long-term benefits.

The item on RTW-expectations was entered as a categorical variable, with positive RTW-expectations as reference category. The confounders were also subjected to the same procedure and examined as predictors of benefit recipiency one by one using binary logistic regression. Second, all variables found to significantly predict benefit recipiency in the unadjusted regression analyses were entered simultaneously in an adjusted regression model.

The basic demographic variables such as gender, age and educational level were included in the adjusted model, whether or not these were statistically significant predictors in the unadjusted analysis. The exact same procedure was then repeated in an unadjusted model, followed by an adjusted model stratified on the three prespecified subgroups. These analyses were performed to examine illness perceptions and RTW-expectations as predictors of benefit recipiency in those at risk of sick leave, currently on sick leave or on long-term benefits. All analyses were performed using Statistical Package for the Social Sciences (SPSS) V.19.0.

\section{RESULTS}

\section{Clinical and demographic characteristics of study population}

The study population consisted of more women than men $(67.1 \%)$ and was characterised by a mean age of 40.4 years and education at university or postgraduate levels (60.5\%). More people scored above the clinical cut-off for anxiety (78\%) compared with depression $(53 \%)$ on the HADS questionnaire, and self-reported average illness duration was 8.6 years. In table 1, we present a full overview of demographic and clinical characteristics, including RTW-expectations and illness perceptions of those at risk of sick leave, on sick leave or on long-term benefits.

\section{Predictors of benefit recipiency at 6-month follow-up regardless of work status at baseline}

In the study population as a whole, uncertain and negative RTW-expectations predicted benefit recipiency at 6-month follow-up (table 2). The fully adjusted model showed that other statistically significant predictors of benefit recipiency were gender (female), illness duration (longer) and self-reported health status (moderate to poor). In the unadjusted model, illness perceptions pertaining to consequences (more and severe) and timeline (long lasting), ascribing many experienced symptoms to the illness (identity), being concerned about the illness (illness concern) and experiencing emotional distress (emotional response) also predicted benefit recipiency.

\section{Predictors of benefit recipiency in subgroups}

Of those at risk of going on sick leave, $264(79.0 \%)$ had managed to maintain their work participation 6 months later. RTW was experienced by $288(54.4 \%)$ of those on sick leave and by $73(22.1 \%)$ of those on long-term benefits.

Group I: At risk of sick leave

For those at risk of going on sick leave, negative RTW-expectations and illness duration (in years) were the only significant predictors of benefit recipiency at 6-month follow-up in the unadjusted model. In the fully adjusted model, negative RTW-expectations remained the single significant predictor for benefit recipiency (table 3).

Group II: On sick leave at baseline

In the unadjusted model for those who were on sick leave at baseline, uncertain and negative RTW-expectations predicted benefit recipiency at 6-month follow-up. The illness perception components, consequences, timeline and identity, were all individual predictors of benefit recipiency in the unadjusted model. In addition, self-reported poor health, perceiving work as detrimental for health, higher scores on mental health status, SHC, occupational grade (blue-collar work) and lower education were also predictors of benefit recipiency. In the fully adjusted model, only uncertain and negative RTW-expectations remained significant predictors of benefit recipiency (table 3).

Group III: On long-term benefits at baseline

In those on long-term benefits, only negative RTW-expectations predicted benefit recipiency in the unadjusted model. In the fully adjusted model, negative RTW-expectations were borderline significant $(\mathrm{p}=0.050)$ while female gender significantly predicted benefit recipiency (table 3).

\section{DISCUSSION}

\section{Main findings}

In this study, we investigated RTW-expectations and illness perceptions as predictors of benefit recipiency in people with CMDs struggling with work participation. We further investigated RTW-expectations and illness perceptions as predictors of benefit recipiency in three prespecified subgroups based on the participants' baseline status: at risk of sick leave, currently on sick leave or on long-term benefits. Uncertain and negative RTW-expectations were strong predictors of benefit recipiency in our study population as a 
Table 1 Baseline demographic and clinical characteristics of participants

\begin{tabular}{|c|c|c|c|c|c|}
\hline & \multirow[b]{2}{*}{ Total } & \multicolumn{3}{|c|}{ Baseline workstatus } & \multirow[b]{2}{*}{$F / \chi$} \\
\hline & & $\begin{array}{l}\text { At risk of sick } \\
\text { leave }(n=334)\end{array}$ & $\begin{array}{l}\text { On sick leave } \\
(n=529)\end{array}$ & $\begin{array}{l}\text { On long-term } \\
\text { benefits }(n=330)\end{array}$ & \\
\hline Women (n (\%)) & $800(67.1)$ & $197(16.5)$ & 375 (31.4) & $228(19.1)$ & $13.9^{*}$ \\
\hline Age & $40.4(9.7)$ & $40.4(9.9)$ & $40.3(9.4)$ & $40.5(9.8)$ & 0.3 \\
\hline University/postgraduate college (n (\%)) & $722(60.5)$ & 213 (17.9) & $327(27.5)$ & $182(15.3)$ & 5.5 \\
\hline Blue-collar workers (n (\%)) & 391 (33.9) & $90(7.8)$ & $166(14.4)$ & $135(11.7)$ & $16.6^{\star}$ \\
\hline Private disability insurance (n (\%)) & 294 (26.2) & $83(7.4)$ & $147(13.1)$ & $64(5.7)$ & $7.5^{\star}$ \\
\hline Beliefs about work and health (1-5)† & $2.9(1.5)$ & $3.2(1.4)$ & $2.5(1.4)$ & $3.1(1.5)$ & $22.7^{\star}$ \\
\hline Illness duration (years) & $8.6(9.7)$ & $8.9(9.7)$ & $6.5(8.5)$ & $11.6(10.08)$ & $23.8^{*}$ \\
\hline \multicolumn{6}{|l|}{ Return-to-Work Expectations (n (\%)) } \\
\hline Positive & 326 (32.3) & $110(10.9)$ & $155(15.4)$ & $61(6.1)$ & $55.3^{*}$ \\
\hline Uncertain & $312(31.0)$ & $63(6.3)$ & $160(15.9)$ & $89(8.8)$ & 0.1 \\
\hline Negative & $370(36.7)$ & $37(3.7)$ & $197(19.5)$ & $136(13.5)$ & $48.1^{*}$ \\
\hline \multicolumn{6}{|c|}{ The Brief-IIIness Perception Questionnaire (B-IPQ) (0-10) } \\
\hline Consequences $\ddagger$ & $7.1(1.9)$ & $6.6(2.1)$ & $7.2(1.8)$ & $7.3(1.8)$ & $15.6^{*}$ \\
\hline Timelineł & $5.9(2.4)$ & $6.0(2.5)$ & $5.5(2.3)$ & $6.5(2.5)$ & $16.7^{\star}$ \\
\hline Personal control & $4.1(2.2)$ & $4.1(2.2)$ & $4.1(2.1)$ & $4.3(2.2)$ & 0.6 \\
\hline Treatment control & $6.9(2.1)$ & $6.9(2.1)$ & $7.0(2.0)$ & $6.6(2.2)$ & $3.7^{\star}$ \\
\hline Identity & $6.6(2.1)$ & $6.3(2.2)$ & $6.6(2.0)$ & $6.9(2.0)$ & $8.2^{*}$ \\
\hline IIIness concern $\ddagger$ & $6.5(2.3)$ & $6.3(2.4)$ & $6.5(2.3)$ & $6.5(2.2)$ & 0.7 \\
\hline Understanding & $6.2(2.4)$ & $6.0(2.5)$ & $6.0(2.4)$ & $6.4(2.5)$ & 2.3 \\
\hline Emotional response & $7.7(2.0)$ & $7.6(2.1)$ & $7.6(2.0)$ & $7.8(1.9)$ & 1.3 \\
\hline \multicolumn{6}{|c|}{ Hospital Anxiety and Depression Scale (HADS) } \\
\hline Total score & $18.8(6.9)$ & $18.3(6.8)$ & $19.1(6.9)$ & $18.5(6.8)$ & 1.6 \\
\hline Anxiety (cut-off=>8) (n (\%)) & $926(78.2)$ & $255(21.5)$ & $421(35.6)$ & $250(21.1)$ & 2.2 \\
\hline Depression (cut-off=>8) (n (\%)) & $633(53.5)$ & $162(13.7)$ & $294(24.8)$ & $177(14.9)$ & 4.3 \\
\hline \multicolumn{6}{|l|}{ Subjective health complaints } \\
\hline Total score & $20.5(10.6)$ & $19.2(10.4)$ & $20.9(10.4)$ & $21.3(11.1)$ & $4.0^{*}$ \\
\hline Self-reported health status $(1-5) \S$ & $2.7(0.8)$ & $2.6(0.8)$ & $2.7(0.8)$ & $2.9(0.8)$ & $10.9^{*}$ \\
\hline \multicolumn{6}{|c|}{$\begin{array}{l}\text { All data are reported as mean (SD) unless stated otherwise }(\mathrm{n}(\%)) \text {. } \\
\text { Significant between-group differences are reported as } \mathrm{F} \text { values or } \chi \text { in the final column to the right. } \\
\text { *Significant at the } 0.05 \text { level. } \\
\text { †Higher score indicates perceiving work participation as more beneficial for health (mental health). } \\
\text { fHigher score indicates more maladaptive illness perceptions. } \\
\S L \text { Lower score indicates better self-reported health status. }\end{array}$} \\
\hline
\end{tabular}

whole, as well as in the subgroup of those currently sick listed. There were differences in the predictive contribution of RTW-expectations and illness perceptions individually and relative to each other depending on the participants' baseline status.

\section{Predictors of non-RTW \\ IIIness perceptions}

Previous studies have shown that illness perceptions predict RTW after myocardial infarction and in musculoskeletal disorders. ${ }^{22} 30$ Furthermore, one study found beliefs about duration and consequences of illness acting as perpetuating factors in long-term sick leave for patients with a variety of disorders. ${ }^{31}$ Our findings seem to show some similarities with previous studies. However, in the current study, the associations were not maintained in the fully adjusted models.

None of the illness perceptions significantly predicted benefit recipiency in the adjusted model for those on sick leave, while uncertain and negative RTW-expectations did. From our previous study, we saw that some of the illness perceptions were particularly strongly associated with uncertain and negative RTW-expectations. ${ }^{25} \mathrm{We}$, therefore, find it plausible to assume that although not statistically significant, predictors of benefit recipiency in this study and illness perceptions may still be part of the underlying factors comprising RTW-expectations. It appears intuitively and clinically sound that perceiving ones' illness as having more severe consequences and affecting more life domains might impact on the RTW-process. One such impact could be asserted on beliefs or decisions related to work participation, for instance, when deciding on readiness to RTW. Furthermore, believing that illness will last for a longer time is likely to impact on how a person perceives the future possibilities for work participation, something that could be involved in the construction and reporting of RTW-expectations. Future studies on RTW in workers on sick leave with CMDs would benefit from including assessments on illness perceptions in order to gain more knowledge on the role these psychological processes might play. 
Table 2 Logistic regression results of RTW-expectations and illness perceptions as predictors of benefit recipiency at 6 -month follow-up in the study population as a whole

\begin{tabular}{|c|c|c|c|c|}
\hline Predictor variables & $\begin{array}{l}\text { Unadjusted model } \\
\text { OR }(95 \% \mathrm{Cl})\end{array}$ & p Value & $\begin{array}{l}\text { Adjusted model } \\
\text { OR }(95 \% \mathrm{Cl})\end{array}$ & p Value \\
\hline \multicolumn{5}{|l|}{ Basic demographics } \\
\hline Gender & $1.18(0.93$ to 1.51$)$ & 0.171 & 1.55 (1.10 to 2.18$)$ & 0.011 \\
\hline Age & $1.00(0.98$ to 1.01$)$ & 0.963 & $1.00(0.98$ to 1.02$)$ & 0.529 \\
\hline Educational level & $0.79(0.62$ to 1.00$)$ & 0.051 & 0.99 (0.68 to 1.43$)$ & 0.968 \\
\hline \multicolumn{5}{|l|}{ RTW-expectations ${ }^{*}$} \\
\hline Uncertain & 1.84 (1.33 to 2.53$)$ & 0.001 & 2.07 (1.39 to 3.06$)$ & $<0.001$ \\
\hline Negative & 3.99 (2.91 to 5.47$)$ & 0.001 & 3.89 (2.61 to 5.79$)$ & $<0.001$ \\
\hline \multicolumn{5}{|l|}{ IIIness perceptions } \\
\hline Consequences & $1.17(1.10$ to 1.25$)$ & $<0.001$ & $1.11(0.98$ to 1.25$)$ & 0.078 \\
\hline Timeline & $1.10(1.05$ to 1.16$)$ & $<0.001$ & $1.03(0.95$ to 1.11$)$ & 0.414 \\
\hline Personal control† & 0.98 (0.93 to 1.03$)$ & 0.527 & & \\
\hline Treatment control† & 0.97 (0.91 to 1.02$)$ & 0.260 & & \\
\hline Identity & 1.16 (1.09 to 1.22$)$ & $<0.001$ & $1.09(0.98$ to 1.21$)$ & 0.083 \\
\hline Illness concern & $1.06(1.01$ to 1.11$)$ & 0.017 & $0.97(0.89$ to 1.06$)$ & 0.977 \\
\hline Understandingt & $1.00(0.96$ to 1.05$)$ & 0.713 & & \\
\hline Emotional response & 1.05 (1.00 to 1.12$)$ & 0.049 & $0.90(0.81$ to 1.00$)$ & 0.066 \\
\hline \multicolumn{5}{|l|}{ Causal attributions } \\
\hline Work & $0.82(0.62$ to 1.08$)$ & 0.173 & & \\
\hline Stress & $0.91(0.62$ to 1.32$)$ & 0.625 & & \\
\hline Personal relationships & $0.83(0.59$ to 1.16$)$ & 0.294 & & \\
\hline \multicolumn{5}{|l|}{ Mental health status } \\
\hline HADS total score & $1.02(1.00$ to 1.04$)$ & 0.009 & 0.99 (0.96 to 1.02$)$ & 0.993 \\
\hline \multicolumn{5}{|l|}{$\mathrm{SHC}$} \\
\hline SHC total score & 1.02 (1.01 to 1.03$)$ & $<0.001$ & $1.00(0.98$ to 1.01$)$ & 0.975 \\
\hline Illness duration (in years) & $1.02(1.01$ to 1.04$)$ & $<0.001$ & 1.03 (1.01 to 1.05$)$ & $<0.001$ \\
\hline Group allocation (intervention vs control) & $1.03(0.82$ to 1.29$)$ & 0.774 & & \\
\hline Blue-collar workers & 1.51 (1.18 to 1.93$)$ & 0.001 & $1.44(0.98$ to 2.10$)$ & 0.057 \\
\hline Private disability insurance & $1.15(0.88$ to 1.50$)$ & 0.292 & & \\
\hline Work and health $\ddagger(1-5)$ & 0.89 (0.82 to 0.97$)$ & 0.008 & $0.94(0.85$ to 1.05$)$ & 0.317 \\
\hline Self-reported health status§ $(1-5)$ & $1.43(1.24$ to 1.65$)$ & $<0.001$ & 1.26 (1.02 to 1.57$)$ & 0.033 \\
\hline \multicolumn{5}{|c|}{$\begin{array}{l}\text { Significant results are highlighted in italics. } \\
\text { ^Reference category: positive RTW-expectations. } \\
\text { †Higher score indicates more adaptive illness perceptions. } \\
\text { †Higher score indicates perceiving work as having more positive effects on health. } \\
\text { §Higher score indicates worse self-reported health status. } \\
\text { HADS, Hospital Anxiety and Depression Scale; RTW, return-to-work; SHC, subjective health complaints. }\end{array}$} \\
\hline
\end{tabular}

\section{RTW-expectations}

Our findings show that psychological factors such as ones' own uncertain or negative RTW-expectations are strong predictors of benefit recipiency in CMDs. This corresponds with previous research showing RTW-expectations to repeatedly predict actual RTW. ${ }^{32-34}$

Previous research findings suggest that health improvement alone is not enough to RTW, and that psychological factors as well are of importance in RTW. ${ }^{35}$ Self-efficacy is essential in the processes that make us initiate and later sustain our behaviours. ${ }^{20}$ Considering RTW-expectations, these expectations would depend on a persons' belief in the ability to RTW. In our study, RTW-expectations predicted benefit recipiency more strongly than symptom severity of CMDs as measured by HADS. This finding is in contrast to one previous study where symptom severity was found to be an important predictor of RTW in a study population resembling the one studied here. ${ }^{13}$ This may be due to the simple fact that this previous study did not include RTW-expectations. However, other studies have found symptom severity to predict RTW also when including RTW-expectations. ${ }^{33}$ The findings from our study might be due to study population characteristics such as an expressed desire to work or the heterogeneous work status. We, therefore, suggest that future studies on work participation or RTW in CMDs include systematic evaluation of participants' RTW-expectations.

In our study, negative RTW-expectations predicted benefit recipiency in those at risk of being on sick leave. This subgroup consisted of people not yet on sick leave that self-reported CMDs as an obstacle for work participation. It is likely that those in this subgroup were on the verge of sick leave. This finding stresses the importance of identifying negative RTW-expectations early in cases where CMDs represent a barrier for optimal work participation. In an occupational healthcare setting, 
Table 3 Significant predictors of benefit recipiency in adjusted logistic regression models for subgroups at risk of sick leave $(n=334)$, on sick leave $(n=529)$ or on long-term disability benefits $(n=330)$

\begin{tabular}{|c|c|c|c|}
\hline $\begin{array}{l}\text { Benefit recipiency at } 6 \text {-month follow-up } \\
\text { Predictor variables } †\end{array}$ & $\begin{array}{l}\text { At risk of sick leave* } \\
n=70 \\
\text { OR }(95 \% \mathrm{Cl})\end{array}$ & $\begin{array}{l}\text { On sick leave }{ }^{\star \star} \\
\mathrm{n}=241 \\
\text { OR }(95 \% \mathrm{Cl})\end{array}$ & $\begin{array}{l}\text { On long-term benefits } \\
\mathrm{n}=257 \\
\text { OR }(95 \% \mathrm{Cl})\end{array}$ \\
\hline \multicolumn{4}{|l|}{ Basic demographics } \\
\hline Gender (women) & $1.83(0.89$ to 3.78$)$ & 1.59 (0.99 to 2.56$)$ & 0.37 (0.17 to 0.79) \\
\hline Age & 0.99 (0.95 to 1.03$)$ & 0.99 (0.97 to 1.02$)$ & 0.99 (0.96 to 1.02$)$ \\
\hline Educational level & 1.06 (0.51 to 2.19$)$ & $0.71(0.45$ to 1.10$)$ & 1.46 (0.79 to 2.69$)$ \\
\hline \multicolumn{4}{|l|}{ RTW-expectations $\ddagger$} \\
\hline Uncertain & $1.92(0.85$ to 4.33$)$ & 2.62 (1.47 to 4.67$)$ & $0.61(0.28$ to 1.30$)$ \\
\hline Negative & 3.03 (1.22 to 7.53$)$ & 3.78 (2.11 to 6.76$)$ & 2.19 (1.00 to 4.79$)$ \\
\hline \multicolumn{4}{|l|}{ Illness perceptions } \\
\hline Consequences & & $1.10(0.94$ to 1.29$)$ & \\
\hline Timeline & & $1.01(0.91$ to 1.13$)$ & \\
\hline \multicolumn{4}{|l|}{ Personal control§ } \\
\hline \multicolumn{4}{|l|}{ Treatment control§ } \\
\hline Identity & & $1.03(0.90$ to 1.18$)$ & \\
\hline \multicolumn{4}{|l|}{ Illness concern } \\
\hline \multicolumn{4}{|l|}{ Understanding§ } \\
\hline \multicolumn{4}{|l|}{ Emotional response } \\
\hline \multicolumn{4}{|l|}{ Causal attributions } \\
\hline \multicolumn{4}{|l|}{ Work } \\
\hline \multicolumn{4}{|l|}{ Stress } \\
\hline \multicolumn{4}{|l|}{ Personal relationships } \\
\hline \multicolumn{4}{|l|}{ Mental health status } \\
\hline HADS total score & & $0.99(0.95$ to 1.03$)$ & \\
\hline \multicolumn{4}{|l|}{$\mathrm{SHC}$} \\
\hline SHC total score & & $1.00(0.98$ to 1.03$)$ & \\
\hline Illness duration (in years) & $1.03(0.99$ to 1.06$)$ & $1.02(0.99$ to 1.05$)$ & \\
\hline \multicolumn{4}{|l|}{ Group allocation (intervention vs control) } \\
\hline Blue-collar workers & & $1.09(0.65$ to 1.84$)$ & \\
\hline \multicolumn{4}{|l|}{ Private disability insurance } \\
\hline Work and health $(1-5)$ & & $0.87(0.75$ to 1.02$)$ & \\
\hline Self reported health status ${ }^{\star *}(1-5)$ & & $1.24(0.93$ to 1.66$)$ & \\
\hline
\end{tabular}

Significant predictors highlighted in italics.

†Investigated in unadjusted logistic regression models for all three subgroups, significant predictors carried forward to adjusted models: ${ }^{*}$ Adjusted for demographic variables gender, age educational level, illness duration and RTW-expectations. ${ }^{* *}$ Adjusted for demographic variables gender, age educational level, RTW-expectations, illness perception components consequences, timeline, identity, mental health and SHC, illness duration, occupational grade, beliefs concerning the effect of work on health and self-reported health status. ${ }^{* * *}$ Adjusted for demographic variables gender, age educational level and RTW-expectations.

‡Reference category: positive RTW-expectations.

$\S$ Higher score indicates more adaptive illness perceptions.

ПHigher score indicates perceiving work as having more positive effects on health.

**Higher score indicates worse self-reported health status.

HADS, Hospital Anxiety and Depression Scale; RTW, return-to-work; SHC, subjective health complaints.

including a focus on peoples' RTW-expectations alongside the focus on mental health improvement could be an important factor in preventing future sick leave episodes and disability resulting from CMDs.

Another important finding of this study was that in those on sick leave, uncertain RTW-expectations predicted benefit recipiency, although not as strongly as negative RTW-expectations. This corresponds with a previous study where uncertain RTW-expectations were associated with a longer time to RTW in workers with soft tissue injuries, with an even stronger association for negative RTW-expectations. ${ }^{36}$

A persons' own predictions of time to RTW, as well as RTW-expectations, have been shown to be better predictors of actual RTW than the opinion of healthcare professionals, ${ }^{33}$ and we therefore suggest that addressing RTW-expectations in occupational healthcare would be useful.

An important characteristic of our study population was that participants' work statuses varied from 'at risk of sick leave' to 'on sick leave' and 'on long-term benefits'. This heterogeneity allowed for investigation of RTWexpectations and illness perceptions across work status. As a result, we were able to reveal that the predictive value of RTW-expectations may vary depending on the work status, thus adding to the literature.

Furthermore, the B-IPQ a reliable and rapid measure, was used to assess the participants' illness perceptions. 
The use of this measure allowed for comparison with other study populations using the B-IPQ and ensured that we measured the participants' actual illness perceptions. The procedure of a one-item measurement of RTW-expectations has previously been demonstrated to be sufficient, ${ }^{37}$ and the single item used to measure RTW-expectations in the present study has been found to measure important aspects of RTW-expectations in patients with low back pain. ${ }^{38}$ In addition, we have previously used this item to investigate the association between illness perceptions and RTW-expectations within the same study population as in the current study. ${ }^{25}$

The use of registry-based data to measure RTW secured a complete follow-up on all participants and eliminates problems associated with other common methods, and is thereby a considerable strength of the study.

Selection bias cannot be ruled out as a potential limitation of our study, as those choosing to join this study could be qualitatively different from those declining to participate. However, as only 17 persons of 1416 screened declined to participate, it can be argued that the study population is a representative sample of the help-seeking population struggling with work participation due to CMDs in Norway.

The classification of cases in this study was based on a hierarchical system that separated those not receiving health-related benefits at all from those receiving such benefits whether these were full or partial. It is possible that a more nuanced classification of cases taking into account partial benefits such as graded sick leave would yield other results.

In this study, we used a version of B-IPQ failing to explicitly ask for participants' perceptions of their CMDs, using the more generic term 'your illness'. This could represent a limitation to our study if participants answered the B-IPQ with other illnesses than CMDs in mind. An important characteristic shared by all participants, however, is that they all enter the study due to CMDs being the primary reason for their struggles with work participation. Hence, we consider this potential limitation to be of little importance.

Recent studies have shown that differences in RTW selfefficacy are more predictive of RTW than RTW-expectations. ${ }^{39}$ Failing to include extensive measures on RTW selfefficacy in our study might represent a limitation. However, no extensive RTW self-efficacy measure is as of yet available in Norwegian language, and we suggest that future studies include such measures when available.

\section{Conclusion}

The current study demonstrates that expectations about ones' own future work participation (RTW-expectations) are strong predictors for future benefit recipiency. Those presenting uncertain or negative RTW-expectations are more likely to be recipients of health-related benefits 6 months later. We suggest that vocational rehabilitation services and occupational healthcare services pay attention to RTW-expectations alongside mental health improvement in workers struggling with work participation due to CMDs.

As previous studies have highlighted, "short-term sick leave may have consequences for future sick leave beyond the effect of ill health". ${ }^{40}$ We believe our findings further stress the importance of identifying negative or uncertain RTW-expectations early on, even before a sick leave episode occurs.

\section{Author affiliations}

${ }^{1}$ Department of Uni Health, Uni Research, Bergen, Norway

${ }^{2}$ Department of Psychosocial Sciences, University of Bergen, Bergen, Norway

${ }^{3}$ Liberty Mutual Research Institute for Safety, Hopkinton, Massachusetts, USA

${ }^{4}$ Department of Family Medicine and Community Health, University of

Massachusetts Medical School, Worcester, Massachusetts, USA

${ }^{5}$ Department of Public Mental Health, Division of Mental Health, Norwegian Institute of Public Health, Bergen, Norway

Acknowledgements Ingrid Blø Olsen contributed to the categorisation of causal attributions on the Brief Illness Perception Questionnaire (B-IPQ) and categorisation of participants' occupational grade.

Contributors CL contributed to data collection, conception and design of the study, performed data analysis, interpreted findings, wrote up the first draft of the study and consequent revisions regarding important intellectual content. WS contributed to critical revision of important intellectual content and revision of analysis. $S \varnothing$ contributed to conception and design of the study, critical revision of the manuscript and its analysis. SER contributed to conception and design of the study, prepared the first draft of the study and its consequent revisions, and oversaw the revision of the study. SER is the guarantor of this study.

Funding The project was commissioned by the Norwegian Ministry of Health and Ministry of Labour and financed through the National Strategy on Work and Mental Health (2007-2012).

Competing interests None.

Patient consent Obtained.

Ethics approval The Regional Committees for Medical and Health Research Ethics (REC), REC West.

Provenance and peer review Not commissioned; externally peer reviewed.

Data sharing statement No additional data are available.

Open Access This is an Open Access article distributed in accordance with the Creative Commons Attribution Non Commercial (CC BY-NC 3.0) license, which permits others to distribute, remix, adapt, build upon this work noncommercially, and license their derivative works on different terms, provided the original work is properly cited and the use is non-commercial. See: http:// creativecommons.org/licenses/by-nc/3.0/

\section{REFERENCES}

1. Waddell G, Burton K. Is work good for your health and well-being? 2006;57:229.

2. Dekkers-Sanchez PM, Hoving JL, Sluiter JK, et al. Factors associated with long-term sick leave in sick-listed employees: a systematic review. Occup Environ Med 2008;65:153-7.

3. Eaton WW, Martins SS, Nestadt G, et al. The burden of mental disorders. Epidemiol Rev 2008;30:1-14.

4. Stansfeld SA, Fuhrer R, Head J. Impact of common mental disorders on sickness absence in an occupational cohort study. Occup Environ Med 2011;68:408-13.

5. Brage S, Nossen JP, Kann IC, et al. Sykefravær med diagnose innen psykiske lidelser 2000-2011. The Norwegian Welfare and Labour Administration, 2012.

6. Knudsen AK, Harvey SB, Mykletun A, et al. Common mental disorders and long-term sickness absence in a general working population. The Hordaland Health Study. Acta Psychiatr Scand 2013;127:287-97. 
7. Knudsen AK, Øverland S, Aakvaag HF, et al. Common mental disorders and disability pension award: seven year follow-up of the HUSK study. J Psychosom Res 2010;69:59-67.

8. Blank L, Peters J, Pickvance S. A systematic review of the factors which predict return to work for people suffering episodes of poor mental health. J Occup Rehabil 2008;18:17-34.

9. Kessler RC, Petukhova M, Sampson NA, et al. Twelve-month and lifetime prevalence and lifetime morbid risk of anxiety and mood disorders in the United States. Int J Methods Psychiatr Res 2012;21:169-84.

10. Knudsen AK, Overland S, Hotopf M, et al. Lost working years due to mental disorders: an analysis of the Norwegian disability pension registry. PLOS ONE 2012;7:e42567.

11. Henderson M, Harvey SB, Overland S, et al. Work and common psychiatric disorders. J R Soc Med 2011;104:198-207.

12. Cornelius LR, van der Klink JJL, Groothoff JW, et al. Prognostic factors of long term disability due to mental disorders: a systematic review. J Occup Rehabil 2011;21:259-74.

13. Brouwers EP, Terluin B, Tiemens BG, et al. Predicting return to work in employees sick-listed due to minor mental disorders. J Occup Rehabil 2009;19:323-32.

14. Nielsen MBD, Bultmann U, Madsen IEH, et al. Health, work, and personal-related predictors of time to return to work among employees with mental health problems. Disabil Rehabil 2012;34:1311-16.

15. Andersen MF, Nielsen KM, Brinkmann S. Meta-synthesis of qualitative research on return to work among employees with common mental disorders. Scand J Work Environ Health 2012;38:93-104.

16. Labriola M, Lund T, Christensen KB, et al. Multilevel analysis of individual and contextual factors as predictors of return to work. $J$ Occup Environ Med 2006;48:1181-8.

17. Shaw WS, Reme SE, Linton SJ, et al. 3(rd) place, PREMUS best paper competition: development of the return-to-work self-efficacy (RTWSE-19) questionnaire-psychometric properties and predictive validity. Scand J Work Environ Health 2011;37:109-19.

18. Lagerveld SE, Blonk RWB, Brenninkmeijer V, et al. Return to work among employees with mental health problems: development and validation of a self-efficacy questionnaire. Work Stress 2010;24:359-75.

19. Bandura A. Self-efficacy: the exercise of control. New York: WH Freeman, 1997.

20. Bandura A. Self-efficacy-toward a unifying theory of behavioral change. Psychol Rev 1977;84:191-215

21. Audhoe SS, Hoving JL, Nieuwenhuijsen K, et al. Prognostic factors for the work participation of sick-listed unemployed and temporary agency workers with psychological problems. J Occup Rehabil 2012:437-46.

22. Hoving JL, van der Meer M, Volkova AY, et al. Illness perceptions and work participation: a systematic review. Int Arch Occup Environ Health 2010;83:595-605.

23. Leventhal H, Benyamini $Y$, Brownlee $S$, et al. Illness representations: theoretical foundations. In: Weinman JA, Petrie KJ, eds. Perceptions of health and illness. Amsterdam: Harwood Academic Publishers, 1997;19-47.

24. Petrie KJ, Broadbent E, Kydd R. Illness perceptions in mental health: issues and potential applications. J Ment Health 2008;17:559-64.

25. Løvvik $\mathrm{C}$, Øverland $\mathrm{S}$, Hysing $\mathrm{M}$, et al. Association between illness perceptions and return-to-work expectations in workers with common mental health symptoms. J Occup Rehabil 2014;24:160-70.

26. Lagerveld SE, Blonk RWB, Brenninkmeijer V, et al. Work-focused treatment of common mental disorders and return to work: a comparative outcome study. J Occup Health Psychol 2012;17:220-34.

27. Zigmond A, Snaith R. The hospital anxiety and depression scale. Acta Psychiatr Scand 1983;676:361-70.

28. Eriksen HR, Ihlebaek C, Ursin H. A scoring system for subjective health complaints (SHC). Scand J Public Health 1999;27:63-72.

29. Broadbent $\mathrm{E}$, Petrie $\mathrm{KJ}$, Main J, et al. The brief illness perception questionnaire. J Psychosom Res 2006;60:631-7.

30. Petrie KJ, Cameron LD, Ellis CJ, et al. Changing illness perceptions after myocardial infarction: an early intervention randomized controlled trial. Psychosom Med 2002;64:580-6.

31. Dekkers-Sanchez PM, Wind H, Sluiter JK, et al. A Qualitative study of perpetuating factors for long-term sick leave and promoting factors for return to work: chronic work disabled patients in their own words. J Rehabil Med 2010;42:544-52.

32. Sampere M, Gimeno D, Serra C, et al. Return to work expectations of workers on long-term non-work-related sick leave. J Occup Rehabil 2012;22:15-26.

33. Nieuwenhuijsen K, Verbeek JH, de Boer AG, et al. Predicting the duration of sickness absence for patients with common mental disorders in occupational health care. Scand J Work Environ Health 2006;32:67-74.

34. Mondloch MV, Cole DC, Frank JW. Does how you do depend on how you think you'll do? A systematic review of the evidence for a relation between patients' recovery expectations and health outcomes. CMAJ 2001;165:174-9.

35. D'Amato A, Zijlstra F. Toward a climate for work resumption: the nonmedical determinants of return to work. J Occup Environ Med 2010;52:67-80.

36. Cole DC, Mondloch MV, Hogg-Johnson S. Listening to injured workers: how recovery expectations predict outcomes-a prospective study. CMAJ 2002;166:749-54.

37. Reme SE, Hagen EM, Eriksen HR. Expectations, perceptions, and physiotherapy predict prolonged sick leave in subacute low back pain. BMC Musculoskelet Disord 2009;10:139.

38. Haldorsen EMH. Return to work in low back pain patients. Bergen: Department of Biological and Medical Psychology.: University of Bergen, 1998

39. Nieuwenhuijsen K, Noordik E, van Dijk FJ, et al. Return to work perceptions and actual return to work in workers with common mental disorders. J Occup Rehabil 2013;23:290-9.

40. Hultin $\mathrm{H}$, Lindholm $\mathrm{C}$, Malfert $\mathrm{M}$, et al. Short-term sick leave and future risk of sickness absence and unemployment-the impact of health status. BMC Public Health 2012;12:861. 